\title{
Usos y abusos del término "neurociencias": una revisión sistemática en revistas indexadas Scielo
}

Uses and abuses of the term "neurosciences": A Systematic Review Based in Indexed Journals Scielo

\section{Moisés Cumpa-Valencia \\ jmcuval@hotmail.com \\ ORCID iD:}

http://orcid.org/0000-0002-

8393-5762

Universidad San Ignacio

De Loyola

\section{Para referenciar este artículo:}

Cumpa-Valencia, M. (2019).

Usos y abusos del término

"neurociencias": una revisión sistemática en revistas indexadas

Scielo. Revista

ConCiencia EPG,

4(1), 30-67.doi:

https://doi.org/10.326

54/CONCIENCIAE

PG.4-1.3

\section{Resumen}

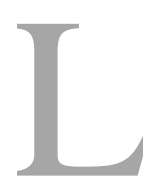

as neurociencias han tenido importantes avances en las tres últimas décadas. Sin embargo, hay cuestionamientos sobre el abuso del término "neurociencias" y del prefijo "neuro" como una forma de dar actualidad a algunas disciplinas e investigaciones. El objetivo de este trabajo es analizar la pertinencia de uso del término "neurociencias" y del prefijo "neuro" mediante tres indicadores: definición explícita o implícita, inclusión en el marco teórico y tipológico de las neurociencias, y desarrollo medular del término en el texto. Se analizaron 29 artículos publicados en la base de datos Scielo desde el año 2000 hasta 2018, que cumplían los criterios de inclusión propuestos. De una escala de pertinencia de uso, se encontraron siete artículos (24\%) catalogados como de pertinencia baja o inferior, lo que implica que el término "neurociencias" y otros con el prefijo "neuro" han sido usados de manera inadecuada. Se recomienda mayor celo y cuidado para la revisión por pares antes de la publicación de los artículos relacionados con las neurociencias o que empleen el prefijo "neuro".

Palabras clave: neuro, neurociencias, neurociencias cognitivas. 


\section{Summary}

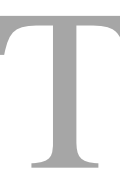

he neurosciences have had important advances in the last three decades. However, there are questions about the abuse of the term "neurosciences" and the prefix "neuro" as a way to give some disciplines and research current status. The objective of this paper is to analyze the relevance of the use of the term "neurosciences" and the prefix "neuro" by means of three indicators: explicit or implicit definition, inclusion in the theoretical and typological framework of the neurosciences, and medullary development of the term in the text. We analyzed 29 articles published in the Scielo database from 2000 to 2018, which met the proposed inclusion criteria. From a scale of pertinence of use, seven articles (24\%) cataloged as low or low relevance were found, which implies that the term "neurosciences" and others with the prefix "neuro" have been used inappropriately. Greater zeal and care is recommended for peer review before the publication of articles related to neurosciences or that use the prefix "neuro".

Keywords: neuro, neurosciences, cognitive neurosciences.

\section{Introducción}

as neurociencias constituyen un conjunto de saberes que se enfocan en estudiar la estructura y el funcionamiento del sistema nervioso, así como la interacción de los elementos del cerebro que dan origen a la conducta de los seres humanos (Blakemore y Frith, 2007; Manes y Niro, 2014), con la finalidad de entender cómo se origina el pensamiento, la conciencia, la interacción social, la creatividad, la percepción, el libre albedrío, la emoción, entre otros hechos, lo que conlleva al carácter multidisciplinario de esta nueva ciencia. En ella deben confluir neurólogos, psicólogos, psiquiatras, filósofos, lingüistas, biólogos, ingenieros, físicos y matemáticos (Manes y Niro, 2014), así como también médicos, sociólogos, teólogos y una larga nómina, ya que comprender el funcionamiento cerebral compete a todos.

De esa interdisciplinariedad surgen algunos campos de estudio que incluyen el prefijo "neuro" y que son aceptados y reconocidos por la comunidad científica. Blakemore y Frith (2007), por ejemplo, definen en su glosario los siguientes:

- Neuroanatomía. - Estudio de la estructura del cerebro.

- Neurobiología. - Estudio de la estructura y la función del cerebro.

- Neurología. - Diagnóstico y tratamiento clínico de pacientes con enfermedades o lesiones neurales.

- Neuropsicología. - Diagnóstico, estudio y tratamiento de personas que han sufrido lesiones cerebrales.

Añaden en dicho glosario tres términos que no aluden a disciplinas, sino a componentes del cuerpo teórico de las neurociencias:

- Neurogénesis. - Generación de nuevas células nerviosas.

- Neuroimágenes. - Técnicas utilizadas para medir la actividad en el cerebro vivo, entre las que se cuentan EEG (electroencefalograma), MEG (magnetoencefalografía) RMf (Resonancia magnética funcional), TEP (tomografía por emisión de positrones).

- Neurotransmisor. - Sustancia química liberada en una sinapsis 
para posibilitar que se transmita información de una neurona a otra.

Manes y Niro (2014), por su parte, definen, además de algunos de los ya mencionados, los siguientes:

- Neuroeconomía. - Estudio de las bases neurales de los procesos cognitivos y emocionales para la toma de decisiones económicas.

- Neuroeducación. - Disciplina que tiene como objetivo el desarrollo de nuevos métodos de enseñanza y aprendizaje combinando pedagogía, neurobiología y ciencias cognitivas.

- Neuroética. - Reflexión sistemática y crítica sobre cuestiones fundamentales en los avances científicos del cerebro, como las implicancias filosóficas, sociales y legales.

- Neurofilosofía. - Estudio de la libertad de decisión de las personas, de su libre albedrío.

- "Neuromarketing". - Los autores colocan este término entre comillas precisamente para cuestionar su carácter científico. Concluyen que no. Supuestamente, mediante este procedimiento se analizan las percepciones de los gustos de los consumidores para predecir su comportamiento de compra.

Complementan su análisis mencionando que hay un acercamiento muy fuerte entre neurobiología y ciencias políticas, ya que el cerebro procesa la información para la vida en sociedad, y que se está comenzando a aceptar el estudio de las bases neurales de la religión dentro de las neurociencias cognitivas.
Precisamente, la mención de neurociencias cognitivas lleva al otro campo denominado neurociencias clínicas.

En el prólogo al libro de Blakemore y Frith (2014), José Marina define la neurociencia cognitiva como el estudio de la base neuronal de los fenómenos conscientes, de nuestros pensamientos, emociones, preferencias, conflictos. Podemos precisar, entonces, que la neurociencia cognitiva aborda los procesos de aprendizaje, lenguaje, inteligencia, creatividad, memoria, conciencia, empatía, entre otras conductas sociales observables. De esa manera, se incluyen la neuroeducación, la neuropsicología, la neuroeconomía, la neuroética, la neurofilosofía, entre otros.

Por su parte, la neurociencia clínica se encarga del estudio de la patología cerebral y el tratamiento de las enfermedades mentales. Se refiere, así, a la psiquiatría clínica, la fenomenología, la psicoterapia, la neurología, la neurocirugía.

Como consecuencia del carácter multidisciplinario de las neurociencias y a la novedad de sus propuestas, ha surgido una moda de anteponer el prefijo "neuro" a cualquier estudio o procedimiento, sea este pertinente o no, tal como lo señalan Corredor y Cárdenas (2017). Entre esos términos, a los que denominan "pseudoacadémicos" mencionan los siguientes: neurolingüística, neuro-insight, neuro-oratoria, neurojurisprudencia, neuro-ingeniería, neurosexología, neuro-estética, neuro-ética, neuro-teología, neuro-historia, neuromúsica, neuro- marketing, neuro- cuántica, neuro- bebidas y psico-neuro-aromaterapia; sin embargo, sí aceptan algunos neurotérminos como neuroeconomía, a la que consideran área de gran crecimiento que explica la toma de decisiones económicas, y neuroeducación, de la que resaltan su integración de neurociencia, pedagogía y 
ciencias de la educación para mejorar el proceso de aprendizaje.

En la misma línea de Corredor y Cárdenas, Calderón (2017) revisa aspectos de la neurociencia actual y cómo se ha generado un "boom" del término "neuro" mediante una creciente oferta de programas, libros y productos de dudosa calidad científica. Menciona como ejemplos neuroeconomía, neuromarketing, neuropolítica, neuroética, y añade, de manera sarcástica, "pasando por la neuroteología, neuroastronomía hasta la neuromagia". No obstante, acepta que algunos estudios "neuro" sí han aportado información relevante y seria. Por ello, propone la divulgación clara y juiciosa de los aspectos conceptuales y metodológicos de las investigaciones, de tal manera que estos resulten comprobables y replicables.

García-Albea (2011) ya cuestionaba el abuso del prefijo "neuro" y del término neurociencia. Considera que este no es más que un sinónimo de neurología; sin embargo, afirma que la neurología ha sido avasallada por la neurociencia y se la ha relegado a las cuestiones clínicas, mientras que la neurociencia ostenta una vocación universalista y se proyecta como una especie de neurocultura. Cita una lista de neurotérminos entre los que incluye neuroeconomía, neuromarketing, neuropsiquiatría, neuromagia, neurofilosofía, neurosociología, neurojurisprudencia, neurogastronomía, y la amplía con otros que considera con "más predicamento" (que debe entenderse como "más confiables"): neuropsicología, neuropedagogía, neurolingüística, neurocomputación y neuroetología. La crítica de García-Albea se extiende a que la neurociencia se ha visto apoyada por el avance de la tecnología, que permite estudiar el cerebro en pleno funcionamiento, y lo compara con una computadora: para comprobar sus usos y funciones tiene poco sentido revisar sus componentes físicos (hardware), porque lo imprescindible es acceder al software.

De lo mencionado, se pueden establecer algunas premisas:

Es una realidad que existe un uso indiscriminado del término neurociencias y del prefijo "neuro" en diversos artículos, productos y servicios.

Existe la necesidad de precisar cuáles son términos con el prefijo "neuro" aceptados- o que pueden ser aceptados- por la comunidad científica según criterios de confiabilidad.

Se requiere un corpus definido de las disciplinas que integran- o pueden integrarlas neurociencias.

Esta revisión sistemática tiene como objetivo central determinar si el uso del término "neurociencias" y otros que contienen el prefijo "neuro" (o asociados a las neurociencias) en los artículos de las revistas indexadas de la base de datos Scielo es pertinente dentro del marco teórico.

Entendemos como prefijo "neuro" al componente morfológico de una palabra compuesta con guion o sin guion como en los siguientes casos: neuropedagogía, neurolingüística, neuroeconomía, neurooratoria, neuro-estética, entre otros.

Entendemos como término asociado a las neurociencias aquellas frases nominales que contienen el término "neurociencias" enlazado mediante la conjunción " $y$ " o la preposición "de", como en los siguientes casos: La relación problemática entre neurociencias y educación, Neurociencias y actividad física, El paradigma de las neurociencias de la educación, entre otros.

En los acápites 2 y 3 se menciona términos "que pueden ser aceptados" por la 
comunidad científica y disciplinas "que pueden integrar" las neurociencias, porque si no se tuviera esa consideración, estaríamos asumiendo que la ciencia es cerrada y completa, cuando se sabe objetivamente que la razón de ser de la ciencia es su desarrollo y cambio constante de paradigmas. La justificación de si los términos pueden ser aceptados o si las disciplinas pueden

\section{Método}

Las revisiones sistemáticas constituyen una forma de investigación que presentan resúmenes acerca de un tema específico. Su centro de estudio se encuentra en bases de datos, metabuscadores, literatura gris, actas de congresos, entre otros (Aguilera, 2014).

\section{Diseño:}

La presente revisión sistemática tiene el carácter de descripción cualitativa sin metaanálisis, es decir, sin análisis estadístico.

\section{Muestra:}

Se revisaron los artículos de la base de datos Scielo del periodo 2000- 2018 que incluyeran el término "neurociencias" o el prefijo "neuro". Luego de aplicar criterios de inclusión y de exclusión se seleccionaron 29.

\section{Criterios de inclusión}

Dentro de los criterios de inclusión, se tomaron en cuenta los siguientes:

- Los artículos fueron seleccionados de la base de datos Scielo, usando las siguientes palabras clave: neuro, neurociencias.

- El término "neurociencias" u otro que empiece con el prefijo "neuro" deben aparecer en el título o en el resumen del artículo. integrarse deberá partir del mismo artículo que los usa o los propone mediante criterios claramente observables.

En ese sentido, y de manera metateórica, esta revisión pretende determinar si en los artículos seleccionados se proponen o cuestionan algunos de los términos relacionados con las neurociencias.

- El estudio debe abordar directa o indirectamente alguna de las siguientes áreas temáticas relacionadas con la neurociencia cognitiva: cerebro (mente, metateoría), comportamiento (actitudes, conducta), educación (aprendizaje, didáctica), sociedad (política, ética, publicidad).

- El idioma de publicación debe ser español

- El año de publicación debe corresponder al intervalo 20002018

\section{Criterios de exclusión}

Dentro de los criterios de exclusión, se tomaron en cuenta los siguientes:

- Artículos netamente médicos o fisiológico (clínicos). Por ejemplo, no se consideró el trabajo titulado Trastornos neuropsiquiátricos en pacientes con encefalitis viral.

- Artículos de índole monográfica o conmemorativa. Por ejemplo, no se consideró el trabajo titulado Momentos históricos y profesores insignes de la neurociencia en Camagüey.

- Artículos de revisiones sistemáticas o metaanálisis. Por ejemplo, no se consideró el trabajo titulado Neurociencias del 
comportamiento en revistas latinoamericanas de psicología.

Los artículos seleccionados fueron organizados en la siguiente tabla 1 , que especifica el ID (número de identificación del artículo para el presente estudio), el autor, el año, el título, el país y el área temática abordada.

Tabla 1

Artículos seleccionados y evaluados

\begin{tabular}{|c|c|c|c|c|c|}
\hline ID & Autor & Año & Título & País & Área Temática \\
\hline 1 & $\begin{array}{l}\text { Escribano- } \\
\text { Cárcel, M. }\end{array}$ & 2018 & $\begin{array}{l}\text { Intimidad humana: ciencias de } \\
\text { la vida, neuroteología } \\
\text { fundamental y ciberfeminismo. }\end{array}$ & España & $\begin{array}{l}\text { Comportamiento, } \\
\text { Sociedad (ética) }\end{array}$ \\
\hline 2 & Bravo, L. & 2018 & $\begin{array}{l}\text { El Paradigma de las } \\
\text { Neurociencias de la Educación } \\
\text { y el Aprendizaje del Lenguaje } \\
\text { Escrito: Una Experiencia de } 60 \\
\text { Años }\end{array}$ & Chile & $\begin{array}{l}\text { Educación, } \\
\text { (aprendizaje) }\end{array}$ \\
\hline 3 & Calzadila, O. & 2017 & $\begin{array}{l}\text { La integración de las } \\
\text { neurociencias en la formación } \\
\text { inicial de docentes para las } \\
\text { carreras de la educación inicial } \\
\text { y básica: caso Cuba }\end{array}$ & Cuba & Educación \\
\hline
\end{tabular}

$4 \quad$ Restrepo, J.; $2017 \quad$ Percepción de neurofobia en

Colombia Educación (aprendizaje)

Aldana, R.; estudiantes de último año de

Álvarez, J.;

Medicina en una universidad

Botero, L.; privada

Durán, M.;

Espinel, B.;

García, D.;

Martín, D.\&

Giraldo, A.

$5 \quad$ Feenstra, R.\& 2017

Pallarés-

Domínguez, D.
Debates éticos en torno al neuromarketing político: el avance tecnológico y su potencial incidencia en la formación de la opinión pública.

$6 \quad$ Sibaja-Molina, 2016

J.; Sánchez-

Pacheco, T.;

Rojas-

Carvajal, M. \&

Fornaguera-

Trías, J.
De la neuroplasticidad a las

propuestas aplicadas:

estimulación temprana y su

implementación en Costa Rica
España

Sociedad (política, ética, publicidad)

Costa Rica

Cerebro, Educación (didáctica) 


7 Castorina, J. 2016

La relación problemática entre

Argentina

Educación

Neurociencias y educación:

Condiciones y análisis crítico

8 Terigi, F. 2016 Sobre aprendizaje escolar y neurociencias

Argentina Educación (aprendizaje)

9 Pérez, D.

2016 ¿Pueden las neurociencias enseñarnos cómo vivir mejor?

10 Cortina, A. 2016 En favor de la libertad. Una perspectiva neuroética

España

Sociedad (política, ética)

11 Paniagua, M. 2016

Pensando otros enfoques en

Bolivia

Educación educación

12 Paniagua, M. 2016

Marcadores del desarrollo

Bolivia

Educación

infantil, enfoque

neuropsicopedagógico

13 Rico, F. \&

Las neurociencias para el

Colombia

Educación

abordaje de la didáctica de las finanzas

14 Silvera, A.; 2016

Resignificación del tejido

Colombia

(didáctica)

Corredor, A.; social: formación de

Pinedaciudadanos eco-lógicos a través

Carreño, M.; de la integración dinámica de las neurociencias.

Pérez, H. \&

Salazar, R.

(2016)

15 Zumalabe- 2016

El estudio neurológico de la

España

Cerebro (mente)

Makirriain, J.

conciencia: una valoración crítica.

16 Abrahan, V. \& 2015

La improvisación musical. Una mirada compartida entre la

Argentina

Comportamiento Justel, N.

musicoterapia y las neurociencias

$17 \quad$ Pautassi, J. 2013

Desde la bioética a la neuroética: ¿neuro-ética o personoética?

Colombia

Sociedad (ética)

Comportamiento (conducta)

18 Figueroa, G. $2013 \quad$ Las ambiciones de la

Chile

Sociedad (ética)

científicamente la moral

19

Paniagua, M.

2013

Neurodidáctica: una nueva

Bolivia

Educación

forma de hacer educación

(didáctica)

20

Buganza, J. 2013

El problema del acto moral en

México

Sociedad (ética), el contexto de las neurociencias 
para una filosofía hilemórfica o

analógica de la mente

$21 \quad$ Puebla, R.\& 2011

Talma, M.

22 Castellanos, S. 2010

23 Álvarez, T.\&

Conde-Guzón, 2009 $\mathrm{P}$.

24 Sierra-

Fitzgerald, Ó, \& Munévar, G.

2007

25 Gutiérrez, G. 2006

26 Saiz, M.\& Amézaga, P.

Educación y neurociencias: La

conexión que hace falta

Chile

Educación

Reflexiones sobre la relación

entre las neurociencias y el

psicoanálisis.

Formación de Subtipos de

Niños con Problemas Escolares

de Aprendizaje a Partir de la

Evaluación Neuropsicológica,

Capacidades Cognitivas y

Comportamiento

Nuevas ventanas hacia el

Colombia

Colombia

(aprendizaje)

Cerebro (mente)

cerebro humano y su impacto

en la neurociencia cognoscitiva

$\begin{aligned} \text { España } & \begin{array}{l}\text { Educación } \\ \text { (aprendizaje) }\end{array} \\ & \begin{array}{l}\text { Comportamiento } \\ \text { (actitudes) }\end{array}\end{aligned}$

Cerebro (mente)

Neurobiología y contenido

Costa Rica

Sociedad (ética)

material universal de la ética:

reflexiones a partir del modelo

neurobiológico de Antonio

Damasio

Psiconeurociencia y arquetipos:

construyendo un diálogo entre

Psicología Analítica y

neurociencia

27 Gallego, J.C. $2004 \quad \begin{aligned} & \text { Evolución y neurociencias: } \\ & \text { Neurobiología, filogenia y }\end{aligned}$

teoría del caos

28 Sepúlveda, J. 2004 Filosofía y neurociencias:

Hegel: la realidad como vida

29 Tizón, J.

¿Por qué "Neurociencias" y no

"Psicociencias"? Godzilla y

Bambi en el reino de la

epistemología

\section{Procedimiento}

Una vez seleccionados los artículos se estableció la pertinencia de uso, que respondería a tres criterios:
1. Que el término con el prefijo neuro (o el término asociado a las neurociencias) esté definido explícita o implícitamente en el texto. El puntaje asignado es el siguiente:

- Definición explícita: 2 puntos 
- Definición implícita: 1 punto

- No presenta definición:0 puntos

2. Que el término con el prefijo neuro (o el término asociado a las neurociencias) esté incluido o pueda incluirse en el marco teórico y tipológico de las neurociencias cognitivas. El puntaje asignado es el siguiente:

- Término incluido:2 puntos

- Término que puede incluirse: 1 punto

- Término que no puede incluirse: 0 punto

3.Que el término con el prefijo neuro (o el término asociado a las neurociencias) corresponda al desarrollo medular del texto y sea usado según su definición o clasificación. El puntaje asignado es el siguiente:

- -Desarrollo medular y usado según definición y clasificación: 2 puntos

- -Desarrollo moderado según definición o clasificación: 1 punto

- -No desarrollado ni usado según definición o clasificación: 0 punto

De lo anterior se desprende la siguiente tabla 2:

Tabla 2

Grado de pertinencia

\begin{tabular}{ll} 
Puntaje & Grado de pertinencia \\
\hline 6 puntos & Pertinencia superior \\
5 puntos & Pertinencia alta \\
4 puntos & Pertinencia media \\
3 puntos & Pertinencia baja \\
2 puntos & Pertinencia inferior \\
1 punto & Pertinencia ínfima \\
0 punto & Pertinencia nula \\
\hline
\end{tabular}

De los tres criterios, tanto el primero como el tercero corresponden al trabajo de campo propio de este tipo de artículos de revisión: lectura atenta y precisa para determinar la definición de los términos implicados, y que su uso corresponda a la propuesta del autor. En cambio, el segundo criterio requiere de un marco conceptual de clasificación de las neurociencias.

Existen diversas clasificaciones. El National Institutes of Health (NIH, s.f.) propone la siguiente:

A) Neurociencia del desarrollo. Descripción del crecimiento $\mathrm{y}$ cambio del cerebro.

B) Neurociencia cognitiva. Estudio de cómo el cerebro crea y controla los pensamientos, el lenguaje, la resolución de problemas y la memoria.

C) Neurociencia molecular y celular. Exploración de los genes, las proteínas y otras moléculas involucradas en el funcionamiento de las neuronas.

D) Neurociencia conductual. Examen de las áreas del cerebro y los procesos relacionados con la conducta de los animales y los seres humanos.

E) Neurociencia clínica. Estudio de trastornos neurológicos $\mathrm{y}$ rehabilitación de pacientes con sistemas nerviosos dañados. Es propio de los neurólogos y psiquiatras.

Sierra-Fitzgerald y Munévar (2017) proponen un árbol de la Neurociencia Cognoscitiva (o cognitiva, según la clasificación del $\mathrm{NIH}$ ), cuyas raíces se encuentran en la Psicología Experimental, la Neurofisiología, la Neuropsicología y las ciencias cognoscitivas, y las nuevas ramas serían la Neurociencia Imagenológica y la Neurofisiología Moderna. Informan, también, que la Neurociencia Cognoscitiva ha transitado por dos paradigmas: el 
Estructuralista - interesado en la comprensión de la cartografía cerebral, iniciado por Broca en 1863- y el Funcionalista, con el concepto de sistema funcional empleado por Luria.

Otra propuesta interesante es la de Ochsner y Lieberman (2001) y Lieberman (2007), quienes distinguen lo siguiente:

A) Neurociencias cognitivas. $\mathrm{Se}$ refieren a los procesos cognitivos como memoria, lenguaje $o$ percepción de la persona.

B) Neurociencia cognitiva social. Analiza cómo los procesos cognitivos afectan y son afectados por las relaciones sociales.

C) Neurociencias sociales. Estudian la influencia del medio ambiente social en el sistema nervioso, inmunológico y endocrino.

Con ánimo didáctico, y mucho de eclecticismo, ya que incorporamos criterios del NIH y de los autores mencionados, en este artículo emplearemos la clasificación subyacente en Blakemore y Frith (2014):

A) Neurociencia cognitiva. Estudio de los fenómenos conscientes como pensamientos, emociones, preferencias, conflictos, que se manifiestan en los procesos de aprendizaje, lenguaje, inteligencia, creatividad, memoria, conciencia, empatía. Se incluye, entonces, la neuroeducación, la neuropsicología, la neuroeconomía, la neurofilosofía, entre otros. En este grupo consideramos la neurociencia conductual y la neurociencia cognitiva social.

B) Neurociencia clínica. Estudio de la patología cerebral y el tratamiento de las enfermedades mentales. Se refiere, así, a la psiquiatría clínica, la fenomenología, la psicoterapia, la neurología, la neurocirugía. En este grupo consideramos la neurociencia del desarrollo y la neurociencia molecular y celular.

Los artículos analizados y seleccionados para efectos del presente estudio corresponden a la neurociencia cognitiva.

\section{Proceso de revisión}

Los artículos seleccionados fueron analizados en su contenido medular, de acuerdo con lo propuesto en el título de cada artículo, así como en el resumen de los mismos. Producto de dicha revisión se elaboró la tabla 3 en que se realiza la síntesis temática de cada artículo

Tabla 3

\section{Síntesis de revisión}

\section{ID Síntesis del artículo}

1 Se adopta una perspectiva interdisciplinar para enlazar la neurociencia con la teología, tomando en cuenta las categorías de análisis de género y de herramientas feministas. Se expone que los dispositivos electrónicos son una presencia que aumenta la funcionalidad humana. Asimismo, que el ejercicio científico se ha utilizado para sojuzgar a las mujeres, a grupos con diversidad funcional, a los colectivos y etnias. Se concluye afirmando que "masculinidad no es sinónimo de universalidad ni que feminización lo sea de precariedad. Se trata de transformar los imaginarios patriarcales y racistas, que también colonizan las comprensiones religiosas y teológicas”. 
2 El autor presenta los aportes de las neurociencias y la psicología cognitiva al aprendizaje del lenguaje escrito basándose en el paradigma científico propuesto por Thomas Kuhn y en su experiencia pedagógica de sesenta años. Establece que el avance de las Neuroimágenes ha permitido mostrar la relación entre procesos cognitivos y aprendizaje.

3 En este artículo se reflexiona acerca de la estrecha relación entre las Neurociencias y la Pedagogía, lo que deriva en una nueva disciplina denominada Neuropedagogía. Se pone en relieve cómo las Neurociencias deberían integrarse en la formación de los docentes

4 En este trabajo se determina la frecuencia de percepción de Neurofobia en los estudiantes de último año de la Universidad de La Sabana y qué factores la generan. Se aplicó una encuesta a 100 estudiantes con preguntas relacionadas con la Neurofobia y se tuvo, entre otros resultados, que el $69 \%$ consideró que las neurociencias tenían un grado de dificultad mayor con respecto a otras especialidades.

$5 \quad$ El artículo se centra en revisar el significado del marketing político, cómo se diferencia de la neuropolítica y los retos éticos que debe afrontar. En ese sentido, se detiene para analizar el papel del principio de autonomía en la teoría política, el cuestionamiento de la eficacia del neuromarketing y la aparición de la neuropolítica como una disciplina que debe ser tomada en cuenta.

6 Uno de los grandes aportes de la neurociencia es el concepto de neuroplasticidad, es decir, de cómo el cerebro es modulado por el ambiente social y educativo. Los autores revisan dicho concepto y lo relacionan con la ET (Estimulación Temprana) presentando la evidencia de algunos métodos para establecer sus alcances y limitaciones.

7 Se revisan las cuestiones filosóficas planteadas por la neurociencia educativa: falacia en las inferencias, confusión en las definiciones, errores categoriales. Además, se exponen las dificultades del marco teórico escisionista, la actividad cerebral para el proceso de aprendizaje y la propuesta de interdisciplinariedad para organizar los estudios de neurociencia educacional.

8 Se analiza la relación objetiva entre neurociencias y educación para enmarcarlo como parte de un problema: el de desplazar formulaciones de otras disciplinas a las formulaciones pedagógicas. Se advierte, entonces, que las investigaciones y aportes de las neurociencias deberían ser analizados y delimitados por los educadores, psicólogos y pedagogos para su aplicación.

9 El autor hace un deslinde entre lo que se considera vida biológica y vida humana, entendiendo a la primera como referida a la salud y a vivir más años, y a la segunda como alusión a la calidad de vida. El vivir mejor que se menciona en el título del artículo implica los dos conceptos. Su tesis se centra en afirmar que el descubrir cómo funciona nuestro cuerpo no nos lleva necesariamente a responder las preguntas relacionadas con cómo se deben hacer las cosas para vivir una buena vida.

10 La autora se pregunta hasta qué punto la persona es libre para decidir una acción o un movimiento y qué relación tiene esta decisión con las funciones cerebrales. Presenta, en ese sentido, la aporía determinismo- libertad, que se supera aceptando la convivencia de dos métodos complementarios: los métodos propios de las ciencias experimentales, 
como la neurociencia, que explica la acción mediante causas observables, y el método que accede a la libertad mediante el lenguaje.

11 La autora presenta casos reales de personas que no han logrado éxito educativo según los estándares y procedimientos actuales. Se cuestiona si el actual sistema educativo es adecuado, ya que se prioriza el desarrollo de la lógica y se desestima el pensamiento creativo y divergente. Propone, en consecuencia, que es urgente revertir esta situación priorizando la creatividad y la innovación sobre la base de los aportes de las neurociencias.

12 El artículo presenta una serie de subtemas relacionados con el desarrollo del niño hasta los seis años de edad aplicando los avances de las neurociencias. Términos como plasticidad cerebral, lateralización de funciones, neuroimágenes, neurodesarrollo psicomotriz, de la función perceptual, de la memoria, del lenguaje, del pensamiento, emocional, además de la función ejecutiva de la inteligencia y madurez cerebral, entre otros, son tratados, aunque de manera muy somera y sin mayores citas en algunos párrafos.

13 A pesar de que el título del artículo anuncia la relación de dos variables: neurociencias y didáctica de las finanzas, a lo largo del artículo, el autor solo aborda los componentes, características y aportes de las neurociencias a la educación en general. La variable "finanzas" solo aparece de manera esporádica y sin mayores luces acerca de sus requerimientos y características.

14 El artículo aborda el concepto de ciudadanía como ligado esencialmente al entorno medioambiental. Ello implica la construcción de una sociedad que respete y cuide el medio ambiente a partir de una formación ecoformativa. Cabe mencionar, sin embargo, que la mención de las neurociencias es coyuntural y esporádica, y no se desarrolla lo anunciado en el título.

15 El autor recorre panorámicamente los estudios neurobiológicos de la conciencia desde el paradigma simbólico computacional hasta los modelos conexionistas que incluyen la relación fenómeno mental- soporte biológico o correlatos neurobiológicos de la conciencia. Se concluye que la conciencia es un producto de la actividad cerebral, pero se aclara que muchas actividades de las neuronas cerebrales no van acompañadas de consciencia.

16 Las autoras realizan una revisión de los avances de la improvisación musical en relación con la musicoterapia y los aportes de las neurociencias: las resonancias magnéticas, las tomografías por emisión de positrones, la introducción de nuevos paradigmas neuropsicológicos refinados permiten conocer la manera como el cerebro procesa y produce la música.

17 El artículo propone un tránsito o proceso de los estudios de la ética que va desde el paso de la bioética a la neuro-ética, pero cuestiona este último término considerando que debería denominarse persono-ética, ya que no es suficiente estudiar lo neurológico, sino la totalidad del ser humano. En ese sentido, el juicio y la conducta moral requieren de la cultura, de la educación.

18 El artículo, luego de distinguir entre la ética de las neurociencias y la neurociencia de la ética, se interesa en la segunda, a la que denomina neuroética fundamental, porque pretende una visión científica de la génesis de la moralidad en el hombre, sienta las 
bases para elaborar una ética universal y replantea los criterios de libre albedrío, determinismo, autonomía, buena voluntad, entre otros.

19 La autora valoriza el aporte de las neurociencias a las diversas ramas del saber, en especial, en este caso, a la educación mediante la Neurodidáctica. Presentas conceptos generales acerca de la educación y de los aportes de la Neurodidáctica, así como las desventajas de las que esta adolece.

20 En el artículo se cuestiona el hecho de pretender que solo sea el cerebro (o la mente, o la corteza prefrontal) el que participa del libre albedrío, de la libertad o del acto moral. Se propone que estos actos son propios del ser humano como unidad hilemórfica, lo que implica que la mente no es una entidad mecánica formada solo por redes neuronales y sinápticas, sino de todo lo que es físicamente el hombre.

21 Los autores realizan una presentación de los aportes y descubrimientos de las neurociencias y las tratan de emparentar con la educación precisando que estos avances se han aplicado preferentemente a la educación especial y que los lazos con el quehacer educativo general en las aulas de clase son aún débiles. Proponen, entonces, una serie de preguntas que podrán servir de marco para establecer un contacto más eficaz entre ambas disciplinas.

22 El autor realiza un recorrido del nacimiento y evolución del psicoanálisis freudiano y concluye que esta rama de la ciencia prescindió de las neurociencias porque estas no ayudaban a comprender cabalmente algunos fenómenos psíquicos, como la histeria. Sin embargo, el autor considera que los principales avances se deberán buscar en el mismo psicoanálisis.

23 El artículo presenta la estrecha relación de la neuropsicología con los avances en la evaluación de los problemas de aprendizaje. Se emplea el instrumento Batería LuriaDNI, que evalúa las funciones neuropsicológicas superiores de los niños en edad escolar, la Escala de inteligencia de Wechsler y la Escala de comportamiento infantil ECI. Se aplicó la batería de instrumentos a 82 escolares, lo que llevó a determinar subtipos de niños con diversos problemas de aprendizaje.

24 El artículo presenta un panorama de la neurociencia cognoscitiva desde sus albores multidisciplinares, la sucesión de paradigmas estructuralistas y funcionalistas hasta llegar a los aportes de la neuroimagenología y la neurofisiología moderna. Concluye preguntándose si se puede ya afirmar que se está gestando un nuevo paradigma basado en los instrumentos tecnológicos de última generación que están permitiendo aclarar el problema de la conciencia.

25 En el texto se analiza cómo el desarrollo de las neurociencias, en especial de la neurobiología, ha influido en el avance de la ética filosófica. Reconoce que en el cerebro no existen centros únicos de la visión o el lenguaje o la racionalidad, sino sistemas compuestos por la interacción de unidades cerebrales interconectadas. Concluye que el criterio de reproducción de la vida es un eje importante para las acciones éticas del ser humano.

26 Los autores proponen un espacio transdisciplinar al que denominan Psiconeurociencia a partir de una re-visión del concepto de arquetipo, propio de la psicología junguiana, y con los aportes de la neurociencia y de la psicología cognitiva. 
27 El autor señala que la organización del mundo natural es solo una apariencia, porque lo que predomina es una larga historia de fenómenos azarosos, impredecibles, acordes con la teoría del caos o con la entropía. Así, el cerebro humano podría funcionar con base en circuitos neuronales reiterativos, que siguen los principios de las ecuaciones de la teoría del caos. Menciona, además, que mediante un sistema filogenético se puede armar una genealogía basada en todos los caracteres fenotípicos. Para ello se requiere una sistematización internacional de esos datos.

28 Sepúlveda propone en su artículo que se debe reemplazar el determinismo por el probabilismo. Asimismo, que los atractores de los sistemas dinámicos corresponden a un conjunto denso de puntos a lo que se puede denominar una dimensión fractal. Enfatiza el autor, por otro lado, el gran avance de la neurociencia a partir de la década de los sesenta: en los últimos cuarenta años se ha otorgado veintitrés premios Nobel relacionados con ella.

29 Después de una nutrida exposición epistemológica sobre el concepto kuhniano de paradigma para no confundirlo con programa de investigación, programa de trabajo o matriz disciplinar, Tizón critica la tendencia reduccionista de llevarlo todo a las neurociencias y no a la psicología: ¿por qué neurociencias y no psicociencias? Y concluye que la psicología como ciencia implica una serie de disciplinas científicas y tecnológicas entre las que se cuentan la psicología evolutiva, la psicopatología, la psicología diferencial, la psicometría, el psicoanálisis, entre otras; mientras que la neurología y la neurociencia vendrían a formar parte de la biología, y que, incluso, mejor sería designarlas como neurotécnicas.

A continuación, se elaboró la tabla 4 en que se analizan los términos referidos a neurociencias o al prefijo "neuro" según los tres indicadores de pertinencia propuestos

Tabla 4

Análisis de términos según criterios de pertinencia de uso

\begin{tabular}{lllll} 
ID & Término & Análisis según criterios propuestos & Resultado & Pertinencia \\
\hline 1 & $\begin{array}{l}\text { Neuroteología } \\
\text { fundamental }\end{array}$ & La autora reflexiona acerca del nuevo concepto y afirma & 1 & 3 puntos: \\
& que "no pretende ser una propuesta más que se sume a la & & Pertinencia \\
& multiplicidad de conocimientos con prefijos neuro". Se & & baja \\
& define de manera implícita neuroteología como el análisis & & \\
& teológico de la realidad aumentada o la visibilidad en & \\
& Internet y sus efectos. Se añade que, dado que Internet & \\
& alberga la memoria, las relaciones sociales y familiares, & \\
& así como nuestros deseos, expectativas y creencias, & \\
& nuestra comprensión de la divinidad y de lo sagrado ha & \\
& cambiado. La neuroteología fundamental, entonces, sería & \\
& un espacio de reflexión que comprende las neurociencias, & \\
& los estudios religiosos, las tecnologías y las teologías. &
\end{tabular}


Dado que se incluyen varios subtemas, como lenguajes y codificaciones tecnológicas, redes, tecnooptimismo, perspectiva de género, ciberfeminismo, entre otros, el concepto de neuroteología fundamental no es desarrollado medularmente. Sin embargo, puede incluirse como parte del corpus tipológico de las neurociencias.

Se anuncia que la neuroteología fundamental debe ser "un espacio intelectual esperanzado para captar teológicamente los límites que presentan las neurociencias". El artículo pretende a) examinar algunos marcos y valores de las ciencias de la vida, b) alertar de los efectos políticos de esos marcos y valores en las mujeres y colectivos marginados, c) ofrecer su propia aproximación crítica.

2 Neurociencias El autor considera que las neurociencias de la educación de la investigan los puntos de contacto entre la biología del Educación sistema nervioso central y los estímulos culturales, (Aprendizaje verbales y emocionales con las estrategias pedagógicas. del lenguaje Explica, asimismo, que emplea el término aprendizaje del escrito) lenguaje escrito porque esto implica una ampliación de la capacidad de pensar y una superación de la acción de "enseñar a leer".

Una de las disciplinas más ligadas a las neurociencias es

6 puntos:

Pertinencia superior la educación y todos los procesos concernientes a ella: enseñanza, aprendizaje, didáctica, pedagogía. Tanto así que se ha formado el término Neuroeducación, aceptado por los investigadores. Precisamente, Bravo concluye mencionando que la combinación de neurociencias y educación constituye una nueva frontera en la ciencia.

El autor informa cómo llegó a las neurociencias leyendo a Luria, Benton y Galaburda, las complementó con lecturas de Vigotsky y Piaget, y las investigaciones de Vellutino, Alegría y Azcoaga. Presenta, además, un recorrido histórico del origen y desarrollo de las neurociencias que desemboca en las Neuroimágenes, las cuales muestran la interacción, velocidad e intensidad de las transmisiones sinápticas durante el proceso educacional.

3 Neurociencias El autor reconoce que el empleo de imágenes de alta y Pedagogía resolución produce una revolución en el conocimiento del cerebro, lo que permite la aparición de las Neurociencias y 6 puntos: Pertinencia su carácter multidisciplinario. En ese devenir, las superior Neurociencias enriquecen a la pedagogía. Esta es una ciencia que tiene como objeto de estudio la educación integral de la personalidad del sujeto. El proceso de instrucción genera cambios cerebrales bajo condiciones 
específicas. Esta situación permite el surgimiento de la Neuropedagogía.

En el artículo se incide en establecer las bases

epistemológicas de la Neuropedagogía, estableciendo sus

diferencias con otros términos estrechamente ligados

como Neuroeducación, Neuroaprendizaje y

Neurodidáctica. Se presenta tablas que integran los

conocimientos neurocientíficos y neuropedagógicos con la

carrera profesional de Educación.

Luego de un recorrido histórico, se llega al auge de las

Neurociencias con su carácter multidisciplinario que conlleva a la formación de nuevas disciplinas como la Neuropedagogía. Esta tiene como objetivo integrar a la Pedagogía el conocimiento del cerebro para guiar la educación, el aprendizaje y la instrucción de la persona.

4 Neurofobia Los autores informan que el término Neurofobia fue usado por primera vez en 1994 por Josefowicz y lo definen como la falta de interés o ansiedad para integrar los conceptos y procedimientos propios de las neurociencias básicas. Es decir, el miedo hacia los temas de las neurociencias y a la aplicación de los conocimientos neurológicos en los pacientes.

El término, a pesar de no estar difundido ampliamente, puede incluirse dentro del marco teórico de las neurociencias. Presenta una definición clara de lo que es un hecho real, como el estudio lo demuestra, que ocurre entre estudiantes de medicina, con el consiguiente procedimiento inadecuado por parte de los futuros médicos hacia los pacientes con enfermedades neurológicas.

En el texto se desarrolla el tema de manera medular, desde la introducción, donde se establece la definición; los resultados, donde se presentan datos referidos a la Neurofobia; y la discusión, donde se determina que la Neurofobia es un fenómeno que dificulta el tratamiento a los pacientes con enfermedades neurológicas.

5 Neuromarketin Los autores reconocen que no existe una definición g político delimitada de neuromarketing 'político, pero proponen que es la disciplina que estudia las bases cerebrales del Pertinencia alta lenguaje político del ser humano, lo que permite organizar alta un discurso político para conectar con la sociedad y captar electores. Definen, asimismo, neuromarketing, basándose en los aportes de Morin, como una rama del marketing que evalúa y analiza el comportamiento y la toma de 
decisiones en referencia a un estímulo para obtener alguna ventaja.

Los autores informan que el neuromarketing ha sido cuestionado en su carácter científico y estratégico. Sin embargo, reconocen que el estudio del cerebro ha permitido establecer avances para conocer la toma de decisiones, ya sea en el mercado (neuromarketing comercial) o en la política (neuromarketing político). En otras palabras, los autores defienden adecuadamente sus propuestas y avanzan con la distinción tipológica entre neuromarketing y neuropolítica.

Se define neuromarketing para luego centrarse en las características, uso y consecuencias éticas del empleo del neuromarketing político, que busca adaptar el mensaje (sonidos, olores, sabores, etc.) para influir en el cerebro. Es decir, se impulsan las decisiones rápidas y emocionales del sistema límbico (cerebro emocional), en desmedro del neocórtex (cerebro racional). Dentro de las críticas al neuromarketing político se encuentran las éticas: el núcleo moral de la democracia está basado en la autonomía de la ciudadanía y no en la manipulación emocional.

6 Neuroplasticid Los autores presentan como sinónimos los términos ad plasticidad cerebral y neuroplasticidad. La definen, basándose en diversos autores, como la capacidad del encéfalo para experimentar cambios funcionales, estructurales y morfológicos en función de la experiencia.

El concepto de neuroplasticidad o plasticidad cerebral es analizado por los autores desde los estudios de mediados del siglo XX cuando Bowlby mostró que la carencia de interacciones cálidas y continuas de los infantes con sus cuidadores en orfanatos derivaba en indicadores negativos de salud mental. Citan los aportes de Piaget y Vigotsky para llegar al conocimiento actual de que el sistema nervioso es capaz de modificarse y adaptarse como producto de la experiencia, especialmente durante la niñez.

Se presenta el sustento de que la premisa básica de la ET (estimulación temprana) es la plasticidad de las personas durante la infancia. Se continúa con los conceptos de plasticidad cerebral y los cambios funcionales, estructurales y morfológicos que conlleva. Se concluye informando acerca de la interacción herencia/medio sobre la plasticidad cerebral, los mecanismos epigenéticos de la regulación de la plasticidad cerebral y su relación con la ET. 
7 Neurociencias El autor acepta el gran desarrollo de las neurociencias, y educación pero, a la vez, reconoce que su aplicación a las prácticas educativas es problemática. Advierte, asimismo, el peligro de caer en el neurologismo y los neuromitos. Basándose en Hruby y Davis, define la neuroeducación como "el estudio del desarrollo de las representaciones mentales que sustentan los progresos cognitivos estudiados por la psicología y las disciplinas didácticas". A partir de dicho concepto, cuestiona la viabilidad de su aplicación.

El término de neurociencia educativa o neuroeducación ya ha sido aceptado por la comunidad científica. Lo que cuestiona el autor es la validez y confiabilidad de este concepto a la luz de los resultados prácticos. Cuestiona Castorina el "aplicacionismo" epistemológico de la neurociencia a la educación y propone la tesis de que la actividad del cerebro es una condición necesaria, pero no suficiente, para el proceso de aprendizaje.

Durante el desarrollo de sus ideas, Castorina emplea los términos neurociencia y educación para probar que para que haya integración entre ambas, se deben satisfacer varias condiciones: la disolución de confusiones conceptuales y la caracterización de las presuposiciones filosóficas adoptadas.

8 Neurociencias y aprendizaje
Basándose en Salas Silva, la autora conviene en definir las neurociencias como el "conjunto de ciencias cuyo sujeto de investigación es el sistema nervioso con particular interés en cómo la actividad del cerebro se relaciona con la conducta y con el aprendizaje". Añade que las neurociencias contribuyen con la educación al ampliar el conocimiento de las bases biológicas del desarrollo humano.

La relación entre las neurociencias y aprendizaje o educación fue una de las primeras en resaltarse. Acerca de esta relación, la autora reflexiona y llega a la conclusión de que aún existe una brecha enorme entre la investigación sobre desarrollo y aprendizaje realizado en las neurociencias, y la investigación sobre el aprendizaje escolar

El interés de Terigi se centra en establecer hasta qué punto los avances en la investigación neurocientífica tienen consecuencias mediatas o inmediatas en la educación. Concluye la investigadora que se debe tener cuidado en pretender reducir el aprendizaje escolar a los nuevos conocimientos acerca del desarrollo de las funciones cerebrales. 
9 Neurociencias No hay una definición explícita de neurociencia, pero y calidad de implícitamente se la asume cuando se manifiesta que la

En este caso, la relación de neurociencias se da con el concepto de vivir mejor. Se podría plantear como neurociencia y vida o neurociencia y calidad de vida. En ese sentido, la autora aborda el concepto de vida diferenciando vida biológica y vida humana. Considera que las neurociencias cumplen un papel meramente descriptivo, lo que las limitan para poder influir de manera decisiva en el vivir bien o el vivir mejor. El tema, sin embargo, ofrece más aristas que pueden tocarse. Por ejemplo, ¿hasta qué punto las neurociencias pueden dejar su aspecto netamente descriptivo para ser más funcionales?

Desde el inicio, la autora desarrolla el tema. Establece su punto de vista con respecto al carácter descriptivo de las neurociencias y cuestiona si es nuestro cerebro el que modula nuestras acciones y por eso es así, o es nuestro accionar, según modelos y conductas culturales, el que ha permitido que nuestro cerebro sea como es. Concluye afirmando que el vivir bien o mejor no es algo causado por lo que acontece en el cerebro, sino por los valores asignados por la sociedad para catalogar lo bueno o lo malo.

10 Neuroética y Los términos por definir son neuroética y libertad. El libertad primero es presentado indirectamente a través de las neurociencias, de las cuales se afirma que son ciencias empíricas y que deben preguntarse por las causas de los acontecimientos; y, por otro lado, relacionando la ética con los sistemas normativos en la vida humana y con el carácter particular de las personas. El segundo es tratado con mayor énfasis desde varias aristas: como participación, como independencia, como no dominación, en el nivel sociopolítico; o como autonomía y libre arbitrio, en el nivel ético y metafísico.

El término neuroética se encuentra en el corpus lexical de las neurociencias cognitivas como una variante de la neurofilosofía. El concepto de libertad corresponde a una de las cuestiones filosóficas que deben ser tratadas de manera central, ya que corresponde a la esencia del ser humano. La autora asume la libertad como un concepto nuclear en la filosofía occidental. Se remonta al siglo VI a.C. mencionando a Heráclito de Éfeso. 
Se plantea en el texto la interrogante de la razón de las cosas, las causas que ocasionaron tal o cual acontecer. Se llegaría a una razón común que ha guiado todo. Sin embargo, tal aserto se contrapone a la conciencia espontánea de los seres humanos para ser libres. Se produce, entonces, la aporía entre el determinismo y la libertad. Se desarrolla el tema basándose en los experimentos de Benjamín Libet. Estos demostraron que los procesos cerebrales determinan las acciones conscientes. Así, no existiría el criterio de libertad, porque el potencial de disposición es anterior a la decisión consciente. La libertad sería, en ese sentido, una ilusión. Frente a ello, otros autores afirman que la libertad sí existe y que el hecho de que la decisión sea posterior a la disposición se explica por los hábitos sociales y el carácter de cada persona influenciado por la ética.

11 Neurociencia, No se presenta el concepto de educación. Se identifica el neuropsicoped problema no tanto de la educación, sino del sistema agogía y educativo. La autora remarca el hecho de que el concepto educación de inteligencia ha cambiado y que ahora hay ocho tipos de inteligencia que no son explotados por el sistema educativo. Sin embargo, con respecto a las neurociencias y la neuropsicopedagogía, a pesar de que las menciona en su resumen, no presenta definición.

Los términos neurociencia y neuropsicopedagogía están aceptados por la comunidad científica para determinar su pertinencia o no a la mejora de la educación. Sin embargo, en el presente artículo, la autora las menciona como soporte de su propuesta que se ciñe a las inteligencias múltiples. Aparentemente, hay una confusión de identidad semántica: se consideran sinónimos neurociencia con inteligencia emocional. O se mencionan neurociencias y neuropsicopedagogía para darle "respaldo" al artículo.

Paniagua empieza su artículo presentando casos de estudiantes que han fracasado según los criterios del sistema educativo imperante, que no considera las inteligencias emocionales y sociales y valoriza solo lo cognitivo. Ante ello, desarrolla el concepto de inteligencias múltiples, entre las que destaca la emocional y la ejecutiva. Concluye que lo mejor es hallar lo propio de cada estudiante, su esencia, lo que le gusta y hace bien. Eso garantizaría el éxito de toda intervención educativa. Sin embargo, de neurociencias y de neuropsicopedagogía no menciona cuáles serían sus aportes.

12 Neuropsicoped Estrictamente no se encuentra una definición de agogía psicopedagogía, aunque la autora aborda conceptualmente 
componentes de dicha rama de la neurociencia, como educación, neuroimágenes, lateralización progresiva de funciones cerebrales, plasticidad cerebral y neurodesarrollo.

4 puntos:

Pertinencia

media

La neuropsicopedagogía fue una de las primeras ramas de la neurociencia en ser identificada con caracteres propios tomados inicialmente de la psicología y de la pedagogía, pero desarrollados a la luz de los avances neurocientíficos. Uno de los conceptos neuropsicopedagógicos tratados en el artículo es el de neurodesarrollo, el cual es presentado en relación al pensamiento, al lenguaje, a lo socioemocional, a la memoria, a la función perceptual.

La autora no desarrolla el concepto de psicopedagogía, sino tangencialmente a través de algunos términos relacionados con esta rama de la neurociencia. No obstante, el abordaje de estos componentes resulta muy general y con escasas citas, lo que pone en duda la confiabilidad del estudio.

13 Neurociencias El artículo se presenta como uno de revisión; en ese y didáctica de sentido, aparece la definición de neurociencias como el las finanzas estudio del sistema nervioso y el funcionamiento cerebral, y su relación con diversos campos de investigación. Sin embargo, a pesar de que hay referencias a la didáctica de manera general, y se menciona que las finanzas se refieren a la administración del dinero, no se encuentra en el artículo definición de didáctica de las finanzas. El autor asume que el lector debe conocer dicho concepto de manera implícita.

Dado que neurociencias es la palabra base y didáctica es el término complementario ya asumido en Neurodidáctica, la reflexión gira en torno de si puede relacionar esta última con las finanzas, formando la frase Neurodidáctica de las finanzas. Visto de esta manera podría resultar una particularidad tipológica que llevaría a atomizar la Neurodidáctica en Neurodidáctica de las matemáticas, Neurodidáctica del lenguaje, Neurodidáctica de la economía, etc. A pesar de ello, consideramos que sí puede incluirse en el canon.

El autor presenta diversos aspectos ya conocidos relación con diversas ramas del saber, la necesidad de la actualización de los docentes en neurociencias y procesos cognitivos, la relación de la nutrición adecuada con el desarrollo del cerebro, pero la didáctica de las finanzas, incluso el término finanzas en solitario, no se aborda de manera exhaustiva. Se menciona en tres o cuatro párrafos, 
lo que constituye una grave falencia con respecto a lo anunciado en el título del artículo.

14 Neurociencias El artículo no presenta una definición de neurociencias. y ecología Con respecto a la ecología, da a entender que ella implica la conservación del medio ambiente sano, condición fundamental para lograr una ciudad autorregulada, equitativa e inclusiva.

Si asumimos que el término ligado a las neurociencias en este artículo es ecología, se generaría la neuroecología. A pesar de que el estudio presentado no desarrolla adecuadamente dicha relación, sino de manera general, consideramos que sí podría incorporarse el término. La actividad cerebral conlleva a la realización de acciones prácticas que pueden inducir a lograr o no una vida social con respeto del medio ambiente.

El estudio se centra en los aspectos ecológicos y Pertinencia inferior ambientales en que el sujeto realiza una acción significativa (cambio de su entorno). Propone que una vida ecológica comunitaria pasa por la gestión de saberes y herencias biológica. La escuela, en ese sentido, está obligada a identificar los factores que permitan gestionar organizaciones sociales inteligentes. No obstante, el término neurociencias solo aparece de manera esporádica. Incluso, en las conclusiones del artículo NO se encuentra.

15 Neurociencias Se presenta en el estudio diversos enfoques tanto de las y conciencia neurociencias como de la conciencia, Para la primera se menciona que algunos autores la definían relacionando metafóricamente la mente con el ordenador (paradigma simbólico- computacional). Asimismo, se propone que las neurociencias, mediante las nuevas tecnologías, permiten explicar la vida mental desde el funcionamiento del cerebro. Con respecto a la conciencia, se afirma que es una actividad que existe a partir del funcionamiento del cerebro: son los procesos cerebrales los que causan las experiencias conscientes.

La relación entre la neurociencia y la conciencia está documentada desde los primeros esbozos de esta nueva ciencia. En el presente artículo, el autor menciona los correlatos neurobiológicos de la conciencia (NCC, por sus siglas en inglés) mediante las propuestas de diversos investigadores.

El autor anuncia que va a presentar una revisión acerca de las aportaciones de las neurociencias y su relación con el estudio de la conciencia, y lo cumple largamente. El panorama abarca desde el paradigma simbólico -

6 puntos:

Pertinencia superior 
computacional hasta los criterios conexionistas. En su análisis crítico, advierte que algunas técnicas imagenológicas pueden resultar poco fiables. Asimismo, que no se pueden explicar los fenómenos mentales con la única base de las estructuras mentales. Hay que tomar en cuenta los factores ambientales y sociales.

16 Neurociencias Casi empezando el artículo, se define la improvisación $\mathrm{y}$ musical relacionándola con las neurociencias: es una musicoterapia conducta creativa compleja que requiere de pensamiento divergente para los contenidos musicales. Se define la musicoterapia como el uso de la música para facilitar y promover la comunicación, las relaciones y el aprendizaje para satisfacer necesidades físicas, emocionales, mentales, sociales y cognitivas.

En el artículo se menciona el surgimiento de una rama

6 puntos: Pertinencia superior denominada Musicoterapia Neurológica (MTN), que se fundamenta en el modelo neurocientífico de percepción y producción musical. Se la define como la aplicación terapéutica de la música en personas con déficits cognitivos, sensoriales y motores causados por enfermedades neurológicas. Dado que la música implica procesos cognitivos superiores y estimula el intelecto, la afectividad y los procesos sensorio-motores, la relación musicoterapia y neurociencias resulta válida.

Las autoras realizan un estudio ordenado según mencionan en el título. Primero se centran en las propiedades y características de la improvisación musical. Luego relacionan esta técnica con las neurociencias enfatizando sus sustratos neuronales y sus efectos fisiológicos. Finalmente, la incluyen como una de las técnicas rehabilitadoras de la musicoterapia.

En el artículo se menciona no solo la definición de neuroética, sino también el origen del término el año 2002 en la conferencia de San Francisco. Sin embargo, cuestiona Pertinencia dicha denominación y propone que debe ser persono-ética, superior porque no puede haber cerebro sin cuerpo. $\mathrm{O}$, en todo caso, propone que se debe pensar en una neuro-ética "global" que incluya la vida física, psíquica y espiritual del ser humano.

El término neuro-ética (separado con guion) o neuroética ya forma parte del corpus de las neurociencias. Lo que se trata en el artículo es la pertinencia de dicha denominación, que, según el autor, debería ser personoética, atendiendo a la complejidad del ser humano que no solo es neurona o mente o cerebro, sino que trasciende 
dicho marco. Es válido, sin lugar a dudas, dicho cuestionamiento.

El autor desarrolla su propuesta presentando los alcances

de la bioética y cómo esta deviene en neuro- ética, término que cuestiona mediante la propuesta de personoética. Así, presenta algunas limitaciones y precisiones: que la neurociencia no puede explicar la moralidad humana; que el modelo de la neuro-ética es simplista y no sistémico; que hay elementos político-económicos que están detrás de la neuro-ética, entre otras conclusiones.

18 Neuroética Se define la neuroética de manera explícita como el

19 Neurodidáctic Se define la Neurodidáctica como una rama de la a estudio de las cuestiones éticas, legales y sociales surgidas a partir de los descubrimientos científicos acerca del cerebro.

El término neuroética se encuentra dentro del corpus de las neurociencias. La relevancia del artículo se manifiesta a partir de la mención de dos vertientes dentro de la neuroética: la ética de las neurociencias frente a la neurociencia de la ética. Juego no de palabras, sino de conceptos. La primera se refiere a los problemas éticos que surgen ante los avances tecnológicos que actúan sobre el cerebro. La segunda estudia los mecanismos neurales que se presentan ante el juicio moral, el libre albedrío, la voluntad, la autonomía, la responsabilidad, entre otras condiciones éticas.

El autor esquematiza la información de los datos experimentales acerca de las cuestiones éticas en cuatro tipos: 1) formulación intuitiva de juicios para los que después se busca argumentos; 2) formulación de juicios mediados por las emociones; 3 ) la ilusión de la libre voluntad; 4) la respuesta rápida si se llega a la conclusión de que algo no se debe hacer. Concluye considerando que la neuroética es un intento serio para explicar el fenómeno de la moralidad. Y que la moral es el resultado de interacciones electroquímicas de las redes neuronales y de programas biológicos al interior del cerebro para tomar decisiones necesarias para la supervivencia del ser humano desde que aparece en la faz de la Tierra. pedagogía basada en las neurociencias cuyo objetivo es diseñar estrategias didácticas y metodológicas que

26 puntos: Pertinencia superior promuevan un mayor desarrollo cerebral, es decir, un mayor aprendizaje.

La Neurodidáctica es una de las ramas de las neurociencias más beneficiadas con los descubrimientos 
acerca del cerebro y las tecnologías desarrolladas para

estudiarlo. Es un término ya establecido y aceptado por la

comunidad científica.

Paniagua presenta un panorama genérico de la

neurodidáctica. Sin embargo, se percibe que en ese afán generalizador, los aportes que menciona para esta rama pueden aplicarse a cualquier proceso de comunicación como puede ser una conversación interesante, la visión de una película o la asistencia al teatro, ya que estas actividades también producen actividades sinápticas y, por consiguiente, una modificación del cerebro.

20 Neurociencias En el artículo se define neurociencias de manera explícita y moral desde un punto de vista funcional: estas tienen como cometido entender la estructura y funcionamiento del cerebro. También se menciona que la neurociencia se dedica a determinar las acciones mecánicas del sistema nervioso. El concepto de moral es tratado como un acto voluntario que puede ser evaluado como bueno o malo, y que implica conocimiento de la finalidad a la cual se dirige. Es decir, el acto moral requiere de la mediación del intelecto.

El estudio de la moral corresponde a la ética. La neuroética es uno de los términos aceptados en el corpus de las neurociencias. El autor informa que el término neuroética no brinda una nueva imagen o definición del ser humano, sino que se enfoca únicamente a valorar qué conductas son mejores en relación con la manipulación cerebral.

$\mathrm{El}$ autor desarrolla la propuesta de que el acto moral no

6 puntos: Pertinencia superior puede ser medido solamente de manera experimental, lo que llevaría a cuestionar o negar la libertad humana. Se requiere una filosofía analógica o hilemórfica (unión de materia y forma) para salvaguardar ontológicamente las dimensiones humanas, entre ellas, la libertad. Las neurociencias explican las indisposiciones cerebrales que disminuyen o anulan la libertad de nuestras decisiones. Pero no se puede decir que la corteza prefrontal decide o que las neuronas deciden: elige el yo, es decir, la persona. Pero lo que diferencia a la persona de los animales irracionales es el intelecto. De ahí se sigue que la moral es un acto voluntario mediado por el intelecto.

21 Neurociencias Se menciona que las neurociencias han contribuido a y educación conocer el funcionamiento del cerebro humano en relación a los tipos de procesamiento de información. Se menciona la educación, pero no se presenta una definición alta explícita de ella 
La relación neurociencias y educación es una de las más

fuertes; sin embargo, los autores cuestionan si realmente hay un aporte decisivo de la primera a la segunda. Y encuentran que aún es muy rala esa conexión. Será labor de los maestros y de los neurocientíficos hallar los puentes conectivos necesarios.

Los autores ponen en el tapete la poca relación y efectividad, hasta el momento, de los aportes de las neurociencias con respecto a la educación. Mencionan que los lazos son débiles y los resultados, pobres. Proponen, en consecuencia, que estos lazos deben ser más fuertes, pero solo ocurrirá cuando los educadores se pregunten qué requieren efectivamente de las neurociencias. Debe tomarse en cuenta que las neurociencias aplican modelos investigativos propios de las ciencias médicas, es decir, positivista y cuantitativo, mientras que la educación responde a criterios cualitativos.

22 Neurociencias La unión de estos dos términos daría lugar al y psicoanálisis neuropsicoanálisis, término que ya aparece en los Estudios clínicos en neuropsicoanálisis de Solms. Castellanos, sin embargo, aborda con recelo este y otros estudios similares, porque no siguen los planteamientos metodológicos del psicoanálisis propuesto por Freud.

A pesar de que Castellanos propone en el título del Pertinencia baja artículo una relación entre neurociencias y psicoanálisis, concluye que hubo una relación inicial que se rompió cuando las neurociencias no pudieron explicar ciertos fenómenos psíquicos. No obstante, y dado que ambas ramas abordan el cerebro y los aspectos neurológicos, consideramos viable la inclusión del término dentro del marco de las neurociencias.

Estrictamente, en el artículo no se aborda el tema del neuropsicoanálisis, sino que se centra en la historia y evolución del psicoanálisis para demostrar que no tiene sustento buscar el desarrollo de este en las neurociencias, sino en el mismo psicoanálisis.

23 Evaluación Se encuentra definida la neuropsicología como el estudio neuropsicológi de las relaciones entre la conducta y el cerebro. 
En el artículo se pone de relieve la aproximación de la neuropsicología al medio escolar. Cita para ello los aportes de Jackson, Orton, Luria y Reitan. Incluso describe que este acercamiento se ha especializado en la evaluación de los problemas de aprendizaje. En ese sentido, las neurociencias han aportado a este desarrollo mediante el mejor conocimiento del cerebro con nuevas tecnologías.

24 Neurociencia Se define explícitamente la neurociencia cognoscitiva cognoscitiva y como la ciencia que busca entender cómo la función cerebro cerebral da lugar a las actividades mentales, tales como la percepción, la memoria, el lenguaje y la conciencia.

La neurociencia cognoscitiva es una de las denominaciones que se da a los estudios de las neurociencias con respecto al entendimiento de las funciones cerebrales. Los autores presentan el término en su real dimensión explicando su origen, desarrollo y perspectivas.

De una manera didáctica, los autores realizan un recorrido de los orígenes de la neurociencia cognoscitiva presentándola metafóricamente como una rama del árbol de las neurociencias, los paradigmas por los que ha transitado (estructuralista y funcionalista), los beneficios de la neuroimagenología y la neurofisiología moderna como instrumentos de investigación que pueden llegar a derivar en un nuevo paradigma.

25 Neurobiología En el artículo hay dos términos implicados: la relación y ética entre neurobiología y ética. El primero es definido tácitamente cuando se menciona la estrecha relación entre Pertinencia superior la corporalidad humana y sus modos de razonar y actuar. La ética es mencionada como parte de una frase: acto ético (proceso corporal- mental) y como parte de un recurso de supervivencia.

Tanto la neurobiología como la ética y la neuroética son términos que se encuentran en la clasificación de las neurociencias. El valor del artículo reside en proponer algunas preguntas para futuras investigaciones: ¿cómo dar cuenta de la complejidad del entorno social y cultural que no puede ser anticipado por la acción parcial y fragmentaria de los participantes?, ¿cómo da cuenta el criterio neurobiológico de una dimensión que es central en la ética, la de la responsabilidad por el otro?

A lo largo del artículo, el autor sigue la propuesta de 
clínico del paciente Gage, quien sufre deterioros en su comportamiento ético, además de su sentido de la responsabilidad hacia sí mismo y los demás, entre otros, Damasio presenta un marco teórico que puntualiza la concepción biológica de los organismos vivos que buscan su reproducción y supervivencia, pero que en el ser humano la constitución de niveles de organización social y racional trascienden dicha dimensión reproductiva y vivencial.

26 Psiconeurocie Los autores definen la Psiconeurociencia como una ncia propuesta interdisciplinar cuyo tema inicial es la relación mente- cerebro, pero que toma en consideración los variados patrones de organización en una red de sistemas arquetípicos, que permitirá la auto-organización y la autoreferencialidad del ser humano para construir su individuación.

La relación entre psicología y neurociencia ya derivó en la neuropsicología. Sin embargo, la propuesta de los autores se centra en la Psiconeurociencia que implica una rama mucho más interdisciplinaria que la neuropsicología. Su base es el criterio de arquetipo, es decir, la existencia de patrones comunes que inciden en la organización, estructura y proceso de la personalidad.

Los autores empiezan precisando que el cerebro es una estructura cognitiva, mientras que la mente es el proceso de cognición que se identifica con el proceso mismo de la vida. Proponen, asimismo, un sistema arquetípico que requiere los aportes de la Psiconeurociencia, la genética de la conducta, la psicología cognitiva, la neurobiología del desarrollo y la psicología simbólico- arquetípica.

27 Neurobiología En el artículo se mencionan los avances de las neurociencias con admiración (una sensación maravillosa poder manipular un genoma recombinante, por ejemplo). No se define neurobiología, pero se remarca la peculiaridad individual de los circuitos neuronales (de reptil, de mamífero y de primate) que surge de una coincidencia del sustrato orgánico, entorno social y familiar, y el momento histórico.

A pesar de que no se ha definido neurobiología, este 5 puntos: Pertinencia alta término se encuentra en la clasificación liminar de las neurociencias. Implica la aceptación de un componente biológico (orgánico, si se quiere) y de un componente neuronal (mental).

El autor aclara que la unión de muchos genes (genómica) y proteína (proteómica) puede ampliar el campo de 
investigación, pero quizá no explique totalmente la enfermedad orgánica o mental. El cerebro es un sistema generado por una conjunción de fenómenos reiterativos de instinto, la necesidad de dejar descendencia, la interacción social, la lucha por los recursos y un ambiente sumamente cambiante. Asimismo, pone de relieve el influjo de los hechos históricos sobre la estructura de la realidad psicosocial. Incide también en que hay una nueva forma de construir la realidad con la teoría del caos.

28 Neurociencias y filosofía, En el artículo no se define ni explícita ni implícitamente el neurofilosofía término neurociencia o neurofilosofía.

El término neurofilosofía es uno de los aceptados en el canon de las neurociencias.

En el artículo se realiza un repaso de los avances de la de la filosofía y la física. Empieza con la dialéctica de Hegel, y pasa por Dubarlé, Lefebvre, la teoría del caos y el efecto mariposa. Luego se menciona los logros de la neurociencia (23 premios Nobel) hasta llegar a la teoría Santiago de la cognición y los aportes de Morin con el paradigma de la complejidad. Culmina remarcando la teoría dialéctica hegeliana.

29 Neurociencias El autor reconoce el desarrollo de las neurociencias, pero y psicociencias lo aborda desde el punto de vista cuestionador de si es correcto el término, ya que considera que todo lo que engloba las neurociencias bien pueden formar parte de las psicociencias, término que propone en lugar del primero. Godzilla simboliza la fuerza del reduccionismo biologista y Bambi representa la indefensión de la psicología.

Luego de la lectura del denso artículo se concluye que el

0 2 Pertinencia media

3 puntos: Pertinencia baja

capítulo de cuestionar la validez del término neurociencias y proponer el de psicociencias es solo eso: un capítulo, ya que lo sustantivo del ensayo es presentar disquisiciones epistemológicas de los paradigmas científicos y de la psiquiatría en particular. Sin embargo, resulta aceptable la propuesta de denominar psicociencias a los estudios propios de las neurociencias.

El autor realiza un deslinde epistemológico del término paradigma, luego cuestiona la pertinencia del término neurociencias en lugar de psicociencias. Sin embargo, el artículo trasciende el título y propone otros temas como el cuestionar si la psiquiatría es ciencia, tecnología, técnica o artesanía clínica, o la presentación de los problemas epistemológicos principales de la psiquiatría. Se asume, entonces, que el tema central es la epistemología y que la mención de las neurociencias resulta uno de los subtemas. 


\section{Resultados}

Con respecto a la cuestión central del grado de pertinencia del uso del término neurociencias y otros que contienen el prefijo neuro (o asociados a las neurociencias) en los artículos, según los criterios propuestos para su revisión, se hallaron los siguientes resultados

Tabla 5

Resultados de Pertinencia de Uso del Término "Neurociencias" y del Prefijo "Neuro"

\begin{tabular}{cccc}
\hline Grado de pertinencia & Puntaje & Número de artículos & Porcentaje \\
\hline Superior & 6 & 12 & $42 \%$ \\
Alta & 5 & 7 & $24 \%$ \\
Media & 4 & 3 & $10 \%$ \\
Baja & 3 & 4 & $14 \%$ \\
Inferior & 2 & 3 & $10 \%$ \\
Ínfima & 1 & 0 & $0 \%$ \\
Nula & 0 & 0 & $0 \%$ \\
& Total & 29 & $100 \%$ \\
\hline
\end{tabular}

Si consideramos que un puntaje de cuatro a seis puntos resulta aceptable según estándares de logro (medio, alto, superior), los artículos que se encuentran en dicho rango constituyen el 76\%, mientras que los artículos con puntaje de 3 y 2 puntos (pertinencia baja e inferior, respectivamente) constituyen el $24 \%$, porcentaje considerable que debe ser tomado en cuenta, porque implica que el abuso del término "neurociencias" y del prefijo "neuro" sí se ha estado manifestando, como analizaremos a continuación.

El artículo 1 de Escribano (2018) logra un puntaje de 3 porque la expresión neuroteología fundamental no es tratada medularmente. La autora aborda diversos subtemas (lenguajes y codificaciones tecnológicas, redes, tecnooptimismo, perspectiva de género, etc.) de tal manera que su propuesta de que la neuroteología fundamental implica la integración de neurociencias, estudios religiosos, tecnologías y teologías queda difuminada.

El artículo 11 de Paniagua (2016) es calificado con 2 puntos porque hay una notoria confusión de conceptos. La autora anuncia en el resumen que va a presentar nuevos enfoques como las neurociencias y la neuropsicopedagogía; sin embargo, centra su propuesta en la teoría de las inteligencias múltiples y el concepto de inteligencia emocional. En ese sentido, se presentan casos de estudiantes que han fracasado según los estándares del sistema educativo actual que prioriza lo cognitivo en desmedro de lo emocional y social.

El artículo 13 de Rico y Puentes (2016) obtiene un puntaje de 2 porque, a pesar de que en el título se anuncia el uso de las neurociencias para el abordaje de la didáctica de las finanzas, en el desarrollo del artículo no hay mayor mención de la frase "didáctica de las finanzas". A lo sumo, el 
término y la frase son mencionados en tres o cuatro párrafos. En todo caso, solo hay referencias a la didáctica en general.

El artículo 14 de Silvera et al. (2016) es calificado con 2 puntos porque anuncia en el título que se va a resignificar el tejido social con ciudadanos eco-lógicos mediante la integración de las neurociencias, pero en el desarrollo solo se enfoca en los aspectos ecológicos y ambientales realizados por el hombre. No se especifica la función de las neurociencias en esa resignificación, tanto así que en las conclusiones no aparece el término.

El artículo 22 de Castellanos (2010) obtiene un puntaje de 3 porque se enfatiza la historia y evolución del psicoanálisis. No desarrolla el término neuropsicoanálisis que podría desprenderse del título del artículo en el cual se anuncia que se va a reflexionar acerca de la relación entre las neurociencias y el psicoanálisis. Incluso, el autor es receloso de esta fusión propuesta en otros estudios, porque no se siguen los planteamientos freudianos.

El artículo 27 de Gallego (2004) recibe el calificativo de 3 puntos porque no se centra estrictamente en la neurobiología (no se define el término de manera explícita ni implícita). Pone de relieve, en cambio, la filogenia, la teoría del caos y la entropía, así como enfatiza que los hechos históricos influyen en la estructura de la realidad psicosocial.

El artículo 29 de Tizón (2002) es calificado con 3 puntos porque la densidad del artículo trasciende el ámbito de las neurociencias y de las psicociencias (término propuesto por el autor). En realidad, el artículo se centra en la epistemología y sus cuestionamientos referidos a si la psiquiatría es ciencia, tecnología, técnica o artesanía, o los alcances y delimitaciones del término paradigma, además de la pertinencia de denominar psicociencias a las neurociencias.

Con respecto al objetivo subyacente, se hallaron algunos artículos en los que se proponen 0 especifican términos relacionados con las neurociencias y otros en los que se cuestiona su validez, especialmente la neuroeducación.

Tabla 6

Propuesta, especificación y cuestionamiento de términos "neuro"

\begin{tabular}{ll}
\hline ID & Detalle \\
\hline $\mathbf{1 7}$ & Propuesta: $\underline{\text { Persono- ética en lugar de neuro-ética }}$ \\
$\mathbf{2 6}$ & Propuesta: $\underline{\text { Psiconeurociencia }}$ \\
$\mathbf{2 9}$ & Propuesta: $\underline{\text { Psicociencias en lugar de neurociencias }}$ \\
$\mathbf{1 8}$ & Especificación: Ética de las neurociencias de neurociencia de la ética \\
$\mathbf{7}$ & Cuestionamiento: $\underline{\text { Neuroeducación }}$ \\
$\mathbf{8}$ & Cuestionamiento: $\underline{\text { Neuroeducación }}$ \\
$\mathbf{2 1}$ & Cuestionamiento: $\underline{\text { Neuroeducación }}$ \\
\hline
\end{tabular}


La propuesta de términos se presenta en los artículos 17, 26 y 29. El artículo 17 de Pautassi (2013) propone la denominación de persono-ética a lo que actualmente se denomina neuro-ética. Sus fundamentos giran en torno a que la persona humana no solo es neurona o mente o cerebro, sino una totalidad que recibe influencia de la cultura, la educación, la política, la economía, el medio social.

El artículo 26 de Saiz y Amézaga (2005) propone una rama científica a la que se denomina Psiconeurociencia. Aparentemente sería una denominación similar o equivalente a neuropsicología, que ya está en el canon de las neurociencias; sin embargo, los autores la entienden como una propuesta interdisciplinar que tiene como base la relación mente- cerebro, pero tomando en cuenta el criterio de arquetipo, es decir, la serie de patrones comunes que forman la personalidad. Este sistema arquetípico requiere los aportes no solo de la Psiconeurociencia, sino de la genética de la conducta, la psicología cognitiva, la neurobiología del desarrollo y la psicología simbólico- arquetípica.

El artículo 29 de Tizón (2002), a pesar de haber recibido un puntaje de 3 (pertinencia baja), propone la denominación de psicociencias en lugar de neurociencias. Se arguye que la psicología abarca un conjunto de disciplinas diferenciadas: psicología evolutiva, psicopatología, psicología diferencial, psicometría, psicoanálisis. En cambio, la neurociencia forma parte de la biología. Se concluye que una disciplina tan amplia (la psicología) no puede estar incluida dentro de una parcialidad (la neurociencia).

La precisión de términos la encontramos en el artículo 18 de Figueroa (2013), quien diferencia, basándose en estudios anteriores, la ética de las neurociencias de la neurociencia de la ética.
La primera se refiere a los problemas éticos que aparecen a partir de las intervenciones y tecnologías que se aplican al cerebro: estimulantes neuronales, neuroimágenes, neuroprótesis, entre otros. La segunda se refiere a los mecanismos neurales relacionados con las condiciones éticas como el juicio moral, el libre albedrío, la voluntad, la autonomía, entre otros.

La crítica a la neuroeducación se presenta en los artículos 7, 8 y 21 . El artículo 7 de Castorina (2016) anuncia desde el título que existe una relación problemática entre las neurociencias y la educación. El principal cuestionamiento es la validez y confiabilidad de la neuroeducación porque los resultados obtenidos hasta el momento no son notorios ni trascendentes. Asimismo, se critica la aplicación epistemológica de los conceptos de la neurociencia a la educación.

El artículo 8 de Terigi (2016) menciona que las neurociencias contribuyen al conocimiento del desarrollo biológico del ser humano, pero advierte que no se puede reducir el proceso de aprendizaje solamente a los factores neuronales o a las funciones cerebrales. Existen otros factores, como las condiciones institucionales de la enseñanza, la ecología del aula, los contenidos escolares.

El artículo 21 de Puebla y Talma (2011) cuestiona si hay un aporte trascendente de las neurociencias a la educación o el aprendizaje. El fundamento es la poca efectividad, dado que los resultados de esta comunión son pobres o ralos. Ante ello, se sugiere que serán los educadores quienes deberán precisar qué requieren efectivamente de las neurociencias.

Un aspecto complementario de la revisión realizada permite señalar que el país que presenta más artículos revisados en esta selección es Colombia (8), seguido por 
España (6) y Argentina (4). Continúan Chile y Bolivia con tres artículos cada uno, y Costa Rica con dos. De Cuba, México y Uruguay se revisaron sendos artículos.

Asimismo, se desprende que la mayoría de los artículos revisados (22)

\section{Discusión}

Como se ha mostrado, siete de los artículos seleccionados (24\%) han obtenido una pertinencia baja e inferior con respecto al uso del término neurociencias y del prefijo neuro. Esto reafirma los temores del abuso ante el "boom" de dichos conceptos (GarcíaAlbea, 2011; Calderón, 2017; Corredor y Cárdenas, 2017).

De los siete artículos mencionados, tres abordan muchos subtemas de los que el referido a las neurociencias resulta opacado. Uno anuncia la neuroteología fundamental (Escribano, 2018), pero desarrolla lenguajes y codificaciones tecnológicas, redes, tecnooptimismo, perspectivas de género, entre otros. Otro anuncia la neurobiología (Gallego, 2004), pero enfatiza la filogenia, la teoría del caos, la entropía, entre otros. El tercero propone la denominación de psicociencias, en lugar de neurociencias (Tizón, 2002), pero prioriza la epistemología, la psiquiatría y las delimitaciones del término paradigma. Es decir, la densidad de conceptos propuestos en cada artículo, así como los subtemas tratados difuminan la relevancia de las neurociencias, lo que desdice lo anunciado en el título o en el resumen. $\mathrm{Si}$ un investigador acudiera a dichas fuentes, encontraría poca sustancia.

Otros tres artículos anuncian, pero no desarrollan el tema propuesto. El primero anuncia la relación neurociencias y didáctica de las finanzas (Rico y Puentes, 2016), pero solo hace referencia a la relación de las fueron publicados a partir de 2010. En cambio, de 2000 a 2009, los artículos seleccionados y revisados suman siete.

neurociencias con la didáctica en general: a didáctica de las finanzas solo le dedica tres párrafos. El segundo anuncia la función de las neurociencias en la resignificación ecológica de los ciudadanos (Silvera et al., 2016), pero no especifica cuál es dicha función. El tercero anuncia la relación entre neurociencias y psicoanálisis (Castellanos, 2010), pero se centra en el psicoanálisis. En estos casos, si bien tienen cierto parecido con el apartado anterior, la mención de neurociencias es coyuntural o nominal, porque no se desarrolla el concepto o la relación o la función.

Los títulos o resúmenes de los artículos mencionados cumplen una labor análoga a la de los titulares y bajadas de la prensa amarilla que anuncian una noticia espectacular o de interés general, pero cuando se acude al desarrollo de la noticia, esta no informa realmente lo anunciado. El solo hecho de comparar un artículo científico con la prensa amarilla resulta claramente contraproducente para el avance de la ciencia.

Un caso especial es el artículo en que se confunde conceptos (Paniagua, 2016). Se anuncia en el resumen el aporte de las neurociencias y la neuropsicopedagogía, pero el artículo se centra en las inteligencias múltiples, en la inteligencia emocional y en el fracaso del sistema educativo actual por no tomar en cuenta dichas inteligencias priorizando lo cognitivo. En todo caso, la mención a las neurociencias resulta muy genérico para lo específico que trata el 
artículo: la aplicación de las inteligencias múltiples en los sistemas educativos. Esta confusión se suma a otras que ya existen en el imaginario socioeducativo: ¿competencias, capacidades o habilidades?, ¿educación por objetivos o por competencias?, entre otras.

Resulta significativo, asimismo, cómo el estudio de las neurociencias permite el aporte de los investigadores para precisar conceptos como ética de las neurociencias para diferenciarla de neurociencia de la ética (Figueroa, 2013) y para proponer nuevos términos como persono-ética en lugar de neuro-ética (Pautassi, 2013), psiconeurociencia (Saiz y Amézaga, 2005) o psicociencias en lugar de neurociencias (Tizón, 2002). Esa es la razón de ser de la investigación para el desarrollo de la ciencia.

Es necesario resaltar que, a pesar de que el término neuroeducación se encuentra dentro del corpus de las neurociencias, existe aún mucho recelo acerca de su confiabilidad y validez por los resultados obtenidos hasta el momento (Castorina, 2016; Terigi, 2016; Puebla y Talma 2011). Incluso estos artículos podrían formar parte de los que cuestionan el uso desmedido del prefijo neuro. El principal factor de esta desconfianza es el carácter multidisciplinario de la educación que no solo toma en cuenta los aspectos neurológicos, sino sociales, económicos, políticos, ambientales, históricos, entre otros.

El hecho de que Colombia sea el país del cual se ha seleccionado la mayor cantidad de artículos con respecto a los demás, permite establecer que en dicho país hay una política educativa que prioriza la investigación en los estamentos universitarios y profesionales.

Por otro lado, a pesar de que se considera el periodo 1990-2000 como la década del cerebro (García-Albea, 2011), las publicaciones durante esa época acerca de las neurociencias eran aún escasas. Es en la actualidad en que están proliferando, con el consiguiente desconcierto de muchas voces que temen el imperio de lo "neuro" y que ha dado lugar a la presente investigación.

A diferencia de García- Albea (2017), que advierte en líneas generales el abuso de lo "neuro", Calderón (2017), que critica la oferta de programas, libros de autoayuda y productos asociados a lo "neuro, y Corredor y Cárdenas (2017), quienes caricaturizan el afán de colocar "neuro" a todo formando "neuro-lo-que-sea", el presente trabajo aporta una sistematización para poder determinar si un artículo científico está empleando de manera pertinente el término "neurociencias" y el prefijo "neuro".

Sin embargo, la limitación principal del estudio se encuentra precisamente en los criterios para determinar la pertinencia de uso. No se encontraron estudios anteriores que permitieran establecer tales criterios, por lo que los empleados en esta revisión resultan una propuesta. Como tal, es factible de ser replicada y mejorada.

Dado su carácter original, en el sentido de verificar el posible abuso del término "neurociencias" y del prefijo "neuro" en revistas indexadas de la base de datos Scielo, quedan abiertas nuevas propuestas para revisar si en otras bases de datos se están empleando dichos conceptos de manera pertinente.

Ante lo expuesto, quedan algunas tareas pendientes. Por parte de las publicaciones, mayor celo y cuidado en el proceso de revisión por pares para que lo anunciado en el título y en el resumen se corresponda con lo desarrollado en el artículo. Por parte de las autoridades educativas, mayor análisis de las corrientes pedagógicas y psicológicas para poderlas 
implementar de manera adecuada y oportuna en aras de un mejor aprendizaje de los estudiantes. Por parte de los educadores, mayor estudio y esfuerzo para enterarse de los avances de la ciencia en general y de las neurociencias en particular que puedan ser aplicados realmente en su labor pedagógica.

\section{Referencias}

Abrahan, V. \& Justel, N. (2015). La Improvisación Musical. Una Mirada Compartida entre la Musicoterapia y las

Neurociencias. Psicogente, 18(34), $372-$

384. https://dx.doi.org/http://doi.org/ 10.17081/psico.18.34.512

Aguilera, R. (2014). ¿Revisión sistemática, revisión narrativa o metaanálisis?

Revista de la Sociedad Española del

Dolor. 21(6) 2.

http://dx.doi.org/10.4321/S113480462014000600010

Álvarez, T. \& Conde-Guzón, P. (2009). Formación de Subtipos de Niños con Problemas Escolares de Aprendizaje a Partir de la Evaluación Neuropsicológica, Capacidades Cognitivas y Comportamiento. Clínica y Salud, 20(1), 19-41. Recuperado de http://scielo.isciii.es/scielo.php?script $=$ sci_arttext\&pid=S1130 $52742009000100003 \& \operatorname{lng}=$ es\&tlng= es

Blakemore, S. J. y Frith, U. (2007). Cómo aprende el cerebro: Las claves para la educación. Barcelona: Ariel

Bravo, L. (2018). El Paradigma de las Neurociencias de la Educación y el Aprendizaje del Lenguaje Escrito: Una Experiencia de 60 Años. Psykhe (Santiago), 27(1), 1-

11. https://dx.doi.org/10.7764/psykhe .27 .1 .1101
Buganza, J. (2013). El problema del acto moral en el contexto de las neurociencias para una filosofía hilemórfica o analógica de la mente. En-claves del pensamiento, 7(13), 23-49.

Recuperado de http://www.scielo.org.mx/scielo.php? script $=$ sci_arttext\&pid=S1870879X2013000100002\&lng=pt\&tlng= es.

Calderón, L. (2017). La Neurociencia: una postura crítica frente al "boom" por la "neuro". CES Psicología, 10(1), 13. Recuperado de http://www.scielo.org.co/scielo.php?s cript=sci_arttext\&pid=S2011$30802017000100001 \& \operatorname{lng}=$ pt $\&$ tlng $=$ es.

Calzadila, O. (2017). La integración de las neurociencias en la formación inicial de docentes para las carreras de la educación inicial y básica: caso Cuba. Actualidades Investigativas en Educación, 17(2), 415441. https://dx.doi.org/10.15517/aie.v $17 \mathrm{i} 2.28709$

Castellanos, S. (2010). Reflexiones sobre la relación entre las neurociencias y el psicoanálisis. Universitas Psychologica, 9(3), 729-735.

Recuperado de http://www.scielo.org.co/scielo.php?s cript=sci_arttext\&pid=S165792672010000300010\&lng=pt\&tlng= es. 
Castorina, J. (2016). La relación problemática entre Neurociencias y educación: Condiciones y análisis crítico. Propuesta educativa, (46), 26-41. Recuperado de http://www.scielo.org.ar/scielo.php?s cript=sci_arttext\&pid=S1995$77852016000200004 \& \operatorname{lng}=$ pt\&tlng $=$ es.

Corredor, K. \& Cárdenas, F. (2017). Neuro«lo que sea»: inicio y auge de una pseudociencia para el siglo XXI. Revista Latinoamericana de Psicología, 49(2), 89-

90. https://dx.doi.org/10.1016/j.rlp.20 17.04 .001

Cortina, A. (2016). En favor de la libertad. Una perspectiva neuroética. Revista latinoamericana de filosofía, 42(1), 15-30. Recuperado de http://www.scielo.org.ar/scielo.php?s cript=sci_arttext\&pid=S1852$73532016000100002 \& \operatorname{lng}=p t \&$ tlng $=$ es.

Escribano-Cárcel, M. (2018). Intimidad humana: ciencias de la vida, neuroteología fundamental y ciberfeminismo. Ex aеquo, (37), 95109. https://dx.doi.org/10.22355/exae quo.2018.37.07

Feenstra, R. \& Pallarés-Domínguez, D. (2017). Debates éticos en torno al neuromarketing político: el avance tecnológico y su potencial incidencia en la formación de la opinión pública. Veritas, (36), 9-

28. https://dx.doi.org/10.4067/S071892732017000100001

Figueroa, G. (2013). Las ambiciones de la neuroética: fundar científicamente la moral. Acta bioethica, 19(2), 259268. https://dx.doi.org/10.4067/S172 6-569X2013000200010
Gallego, J. C. (2004). Evolución y neurociencias: Neurobiología, filogenia y teoría del caos. Revista Colombiana de Psiquiatría, 33(Supl. 1), 25-36. Recuperado de http://www.scielo.org.co/scielo.php?s cript=sci_arttext \&pid=S0034$74502004000500003 \& \operatorname{lng}=$ pt\&tlng $=$ es.

García- Albea, J.E. (2011). Usos y abusos de lo "neuro". Revista de Neurología. 52(10, 577-580. Recuperado de https://www.neurologia.com/articulo/ 2010313

Gutiérrez, G. (2006). Neurobiología y contenido material universal de la ética: reflexiones a partir del modelo neurobiológico de Antonio Damasio. Utopìa y Praxis Latinoamericana, 11(33), 009-038. Recuperado de http://www.scielo.org.ve/scielo.php?s cript=sci_arttext\&pid=S1315$52162006000200002 \& \operatorname{lng}=$ pt\&tlng= es.

Lieberman, M. (2007). Social cognitive neuroscience: A review of core processes. Annu. Rev. Psychol, 58, 259-289.DOI: $10.1146 /$ annurev.psych.58.110405.085654

Manes, F. y Niro M. (2014). Usar el cerebro: Conocer nuestra mente para vivir mejor. Buenos Aires: Planeta.

National Institutes of Health (s.f.). ¿Cuáles son las diferentes áreas de la neurociencia? Recuperado de https://www1.nichd.nih.gov/espanol/ salud/temas/neuro/informacion/Pages /areas.aspx

Ochsner, K. y Lieberman, M. (2001). The emergence of social cognitive neuroscience. American Pschylogist, 
56(9), 717-734. Doi: 1037//0003-

066x.56.9.717

Paniagua, M. (2013). Neurodidáctica: una nueva forma de hacer educación. Fides et Ratio - Revista de Difusión cultural y científica de la Universidad La Salle en Bolivia, 6(6), 72-77. Recuperado de http://www.scielo.org.bo/scielo.php? script $=$ sci_arttext\&pid=S2071081X2013000100009\&lng=pt\&tlng= es.

Paniagua, M. (2016). Marcadores del desarrollo infantil, enfoque Neuropsicopedagógico. Fides et Ratio - Revista de Difusión cultural y científica de la Universidad La Salle en Bolivia, 12(12), 81-99.

Recuperado de http://www.scielo.org.bo/scielo.php? script=sci_arttext\&pid=S2071 081X2016000200006\&lng=pt\&tlng= es.

Paniagua, M. (2016). Pensando otros enfoques en educación. Fides et Ratio - Revista de Difusión cultural y científica de la Universidad La Salle en Bolivia, 11(11), 87-99.

Recuperado de http://www.scielo.org.bo/scielo.php? script=sci_arttext\&pid=S2071081X2016000100006\&lng=pt\&tlng= es.

Pautassi, J. (2013). Desde la bioética a la neuro- ética: ¿Neuro- ética o persono-ética? Revista Latinoamericana de Bioética, 13(2), 48-59. Recuperado de http://www.scielo.org.co/scielo.php?s cript=sci_arttext\&pid=S1657$47022013000200005 \& \operatorname{lng}=$ pt\&tlng $=$ es.

Pérez, D. (2016) ¿Pueden las neurociencias enseñarnos cómo vivir mejor? Revista latinoamericana de filosofía, 42(1), 95-108. Recuperado de

http://www.scielo.org.ar/scielo.php?s cript=sci_arttext\&pid=S1852$73532016000100007 \& \operatorname{lng}=p t \& \operatorname{lng}=$ es.

Puebla, R. \& Talma, M. (2011). Educación y neurociencias: La conexión que hace falta. Estudios pedagógicos (Valdivia), 37(2), 379388. https://dx.doi.org/10.4067/S071 8-07052011000200023

Restrepo, J., Aldana, R., Álvarez, J., Botero, L., Durán, M., Espinel, B., García, D., Martín, D. \& Giraldo, A. (2017). Percepción de neurofobia en estudiantes de último año de Medicina en una universidad privada. Acta Neurológica Colombiana, 33(2), 6367. https://dx.doi.org/10.22379/2422 4022135

Rico, F. \& Puentes, P. (2016). Las neurociencias para el abordaje de la didáctica de las finanzas. Psicogente, 19(35), 161176. https://dx.doi.org/10.17081/psic o.19.35.1216

Saiz, M. \& Amézaga, P. (2005).

Psiconeurociencia y arquetipos: construyendo un diálogo entre Psicología Analítica y neurociencia. Psicología USP, 16(3), 95

117. https://dx.doi.org/10.1590/S010 3-65642005000200006

Sepúlveda, J. (2004). Filosofía y neurociencias: Hegel: la realidad como vida. Revista Colombiana de Psiquiatría, 33(Supl. 1), 9-24.

Recuperado de http://www.scielo.org.co/scielo.php?s cript=sci_arttext\&pid=S0034- 
$74502004000500002 \& \operatorname{lng}=p t \& \operatorname{lng}=$

es.

Sibaja-Molina, J.; Sánchez-Pacheco, T.; Rojas-Carvajal, M. \& Fornaguera-

Trías, J. (2016). De la

neuroplasticidad a las propuestas

aplicadas: estimulación temprana y

su implementación en Costa

Rica. Revista Costarricense de

Psicología, 35(2), 94-112.

Recuperado de

http://www.scielo.sa.cr/scielo.php?sc

ript=sci_arttext\&pid=S1659-

$29132016000200094 \& \operatorname{lng}=$ pt\&tlng $=$ es.

Sierra- Fitzgerald, Ó. \& Munévar, G.

(2017). Nuevas ventanas hacia el cerebro humano y su impacto en la neurociencia cognoscitiva. Revista

Latinoamericana de

Psicología, 39(1), 143-157.

Recuperado de

http://www.scielo.org.co/scielo.php?s cript=sci_arttext\&pid=S0120-

05342007000100010\&lng=pt\&tlng= es.

Silvera, A.; Corredor, A.; Pineda-Carreño, M.; Pérez, H. \& Salazar, R. (2016). Resignificación del tejido social: formación de ciudadanos ecológicos a través de la integración dinámica de las neurociencias. Producción
Limpia, 11(1), 129-140. Recuperado

de

http://www.scielo.org.co/scielo.php?s cript=sci_arttext\&pid=S190904552016000100013\&lng=pt\&tlng= es.

Terigi, F. (2016). Sobre aprendizaje escolar y neurociencias. Propuesta educativa, (46), 50-64. Recuperado de http://www.scielo.org.ar/scielo.php?s cript=sci_arttext\&pid=S1995$77852016000200006 \& \operatorname{lng}=\mathrm{pt} \& \operatorname{tlng}=$ es.

Tizón, J. (2002). ¿Por qué "Neurociencias" y no "Psicociencias"?: Godzilla y Bambi en el reino de la epistemología. Revista de la Asociación Española de Neuropsiquiatría, (84), 67-117. Recuperado de http://scielo.isciii.es/scielo.php?script =sci_arttext\&pid=S0211$57352002000400005 \& \operatorname{lng}=$ pt\&tlng $=$ es.

Zumalabe-Makirriain, J. (2016). El estudio neurológico de la conciencia: una valoración crítica. Anales de Psicología, 32(1), 266278. https://dx.doi.org/10.6018/anale sps.31.3.184411. 